\title{
SISTEM PAKAR DIAGNOSA KERUSAKAN PADA ALAT BERAT MENGGUNAKAN METODE FORWARD CHAINING
}

\author{
Tika Christy ${ }^{1}$, Ilwan Syafrinal ${ }^{2^{*}}$ \\ ${ }^{1}$ Sistem Informasi, STMIK Royal Kisaran \\ ${ }^{2}$ Komputerisasi Akuntansi, Universitas Catur Insan Cendekia \\ email:*ilwansynl@gmail.com
}

\begin{abstract}
Abstrack: The ability of computers to remember and store information properly can be utilized without having to depend on deficiencies that humans have, such as hunger, thirst and emotions that can be felt at any time as humans. Except for electrical energy, all human weaknesses in remembering something can be done by a computer without obstacles. This forward tracking is a data-driven approach. In this approach tracking starts with input information, and then tries to draw conclusions. The basic concept of an expert system where the user submits information or facts to the expert system then the user receives a solution or answer from the expert system. Expert System Application to Detect Heavy Equipment Damage at PT.Tamako Raya Perdana was made so that it can help Heavy Equipment Operators (Excavators) or Companies, and may be able to help Mechanics if they forget the mechanism of action on Heavy Equipment (Excavators). So they no longer need to bother to get the information they need in handling problems in the Excavator.
\end{abstract}

Keyword: expert system, forward chaining, heavy equipment

\begin{abstract}
Abstrak: Kemampuan Komputer untuk mengingat dan menyimpan informasi dengan baik dapat dimanfaatkan tanpa harus bergantung kepada kekurangan-kekurangan yang dimiliki manusia, seperti lapar, haus dan emosi yang sewaktu-waktu bisa dirasakan seperti pada manusia. Kecuali karena energy listrik, semua kelemahan manusia dalam mengingat sesuatu bisa dilakukan oleh komputer tanpa kendala. Pelacakan kedepan atau runut maju ini adalah pendekatan yang dimotori data (data-driven). Dalam pendekatan ini pelacakan dimulai dari informasi masukan, dan selanjutnya mencoba menggambarkan kesimpulan. Konsep dasar sistem pakar dimana pengguna menyampaikan informasi atau fakta untuk sistem pakar kemudian pengguna menerima solusi atau jawaban dari sistem pakar. Aplikasi Sistem Pakar Untuk Mendeteksi Kerusakan Alat Berat Pada PT.Tamako Raya Perdana ini dibuat agar dapat membantu para Operator Alat Berat (Excavator) atau Perusahaan, dan mungkin dapat membantu Mekanik bila lupa akan mekanisme kerja pada Alat Berat (Excavator). Sehingga mereka tidak perlu lagi bersusah payah untuk mendapatkan informasi yang mereka butuhkan dalam menangani masalah-masalah pada Excavator tersebut.
\end{abstract}

Kata kunci : sistem pakar, runut maju, alat berat 
DOI: https://doi.org/10.33330/jurteksi.v6i1.449

Available online at http://jurnal.stmikroyal.ac.id/index.php/jurteksi

\section{PENDAHULUAN}

Kemampuan Komputer untuk mengingat dan menyimpan informasi dengan baik dapat dimanfaatkan tanpa harus bergantung kepada kekurangankekurangan yang dimiliki manusia, seperti lapar, haus dan emosi yang sewaktu-waktu bisa dirasakan seperti pada manusia. Kecuali karena energy listrik, semua kelemahan manusia dalam mengingat sesuatu bisa dilakukan oleh komputer tanpa kendala. Dengan menyimpan informasi dan digabungkan dengan himpunan aturan penalaran yang memadai memungkinkan komputer memberikan kesimpulan atau mengambil keputusan yang kualitasnya sama dengan kemampuan seorang pakar bidang keilmuan tertentu, meskipun tidak dapat menggantikan pakar secara keseluruhan.

[1] keahlian dipindahkan dari pakar ke suatu komputer. Pengetahuan ini kemudian disimpan di dalam komputer. Pada saat pengguna menjalankan komputer untuk mendapatkan informasi, system pakar menanyakan fakta-fakta dan dapat membuat penalaran (inferensi) dan sampai pada suatu kesimpulan. Kemudian, system pakar memberikan penjelasan (memberikan kesimpulan atas hasil konsulasi yang telah dilakukan sebelumnya).

Jadi, sistem pakar adalah perangkat lunak komputer yang memiliki basis pengetahuan untuk domain tertentu dengan menggunakan penalaran inferensi menyerupai seorang pakar dalam memecahkan suatu masalah.

Konsep dasar sistem pakar dimana pengguna menyampaikan informasi atau fakta untuk sistem pakar kemudian pengguna menerima solusi atau jawaban dari sistem pakar [2]. Berikut ini merupakan gambar konsep dasar sistem pakar.

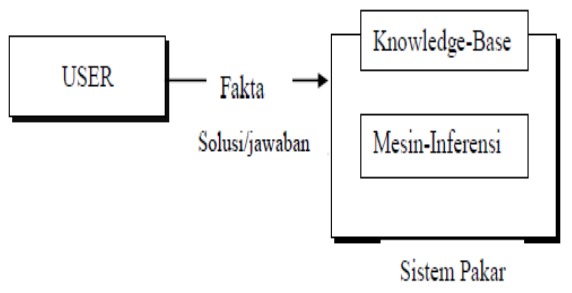

Gambar 2. Konsep Dasar Sistem Pakar

Forward Chaining (Runut Maju)

Forward chaining adalah suatu strategi pengambilan keputusan yang dimulai dari premis (fakta) menuju konklusi (kesimpulan akhir) [3]. Pelacakan kedepan atau runut maju ini adalah pendekatan yang dimotori data (data-driven). Dalam pendekatan ini pelacakan dimulai dari informasi masukan, dan selanjutnya mencoba menggambarkan kesimpulan. Metode inferensi ini yang akan digunakan dalam sistem pakar yang akan dibangun dengan contoh penalaran sebagai berikut.

IF Tidak berfungsinya panel

AND Tidak berfungsinya motor gas

AND Komputer alat berwarna merah

THEN Elektrik rusak

Secara sederhana dapat dijelaskan bahwa untuk kaidah diatas, agar system mencapai konklusi, harus diinput terlebih dahulu fakta tidak berfungsinya panel, tidak berfungsinya motor gas dan komputer alat berwarna merah. Baru system dapat mengeluarkan konklusi bahwa kerusakan adalah elektrik rusak.

\section{METODE}

Kerangka kerja dalam penelitian 
DOI: https://doi.org/10.33330/jurteksi.v6i1.449

Available online at http://jurnal.stmikroyal.ac.id/index.php/jurteksi

ini dimulai dari Pengumpulan Data, Analisa, Perancangan dan Implementasi.

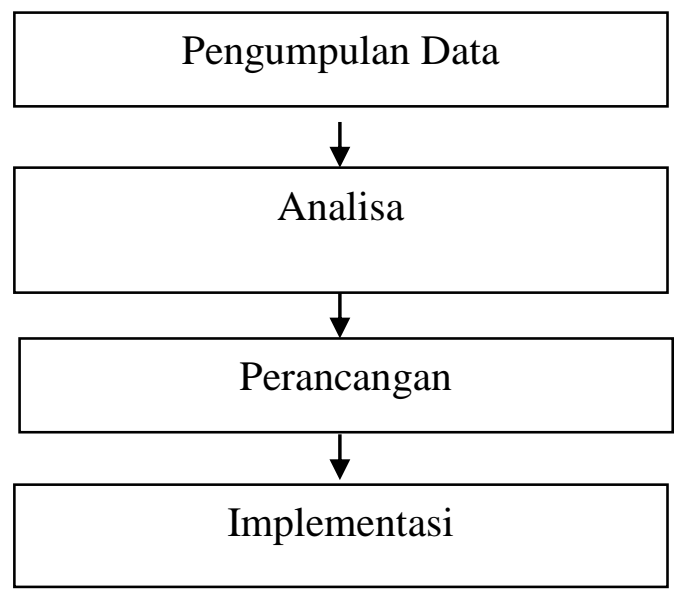

Gambar 2. Kerangka Kerja Penelitian

a. Pengumpulan Data

Studi ini dilakukan dengan mengumpulkan data yang ada hubungannya dengan penelitian ini yang bersifat teoritis dengan cara membaca buku, majalah-majalah dan tulisan yang berkaitan erat dengan penelitian. Studi ini juga bertujuan untuk menguatkan dasardasar pengerjaan penelitian ini sehingga tidak terlepas dari ketentuan yang berlaku.

b. Analisa

Analisis/analisa sistem adalah penguraian dari suatu sistem informasi yang utuh kedalam bagian-bagian komponennya dengan maksud untuk mengidentifikasikan dan mengevaluasi permasalahan-permasalahan, kesempatankesempatan, hambatan-hambatan yang terjadi dan kebutuhan-kebutuhan yang diharapkan sehingga dapat diusulkan perbaikan-perbaikan.

c. Perancangan

Desain didalam suatu sistem adalah suatu kegiatan atau kerja untuk membuat desain atau gambaran tentang sistem yang akan diimplementasikan.

d. Implementasi Sistem

Implementasi sistem merupakan prosedur yang dilakukan untuk menyelesaikan desain sistem yang ada dalam dokumen desain yang disetujui, menguji sistem, menginstal, dan memulai sistem yang baru yang telah diperbaiki

\section{ANALISA DAN PEMBAHASAN}

\section{Analisis Kerusakan}

Pada bagian ini akan diuraikan permasalahan atau kerusakan yang umum terjadi pada Excavator Comatsu Strep 6. Untuk mengetahui penyebabnya dan menentukan jalan keluar atau penanganannya, perlu diketahui dahulu gejala-gejala atau tanda-tanda kerusakan yang ditimbulkan. Dari gejala-gejala atau tanda-tanda yang terlihat secara langsung maupun gejala yang terdeteksi melalui pengecekan, mekanik dapat mengambil suatu kesimpulan berupa kerusakan pada alat berat. Tetapi ada kalanya diperlukan pengecekan lebih lanjut melalui pengecekan secara intensif untuk kerusakan tertentu.

Berdasarkan penelitian dan wawancara dengan mekanik alat berat pada PT.Tamako Raya Perdana terdapat beberapa jenis kerusakan yang sering tejadi pada excavator strep 6 comatsu PC 200, yaitu:

a.Seal Boom Bocor

b.Elektrik Rusak

c.Fuel Injeksi Pump Lemah

d.Selenoid Pompa Hidrolik Terbakar

e.Seal Travel Motor Bocor

f.Mesin (Engine) Ngedrop

g.Trek lemah (tidak kuat) 
JURTEKSI (Jurnal Teknologi dan Sistem Informasi)

Vol. VI No. 1, Des 2019, hlm. 93 - 100

DOI: https://doi.org/10.33330/jurteksi.v6i1.449

Available online at http://jurnal.stmikroyal.ac.id/index.php/jurteksi
ISSN 2407-1811 (Print)

ISSN 2550-0201 (Online)
h.Gas Tidak Bekerja Dengan Normal

i.Rem Swing Rusak

j.Swing Lemah (tidak ada pergerakan)

k.Engine Over Head (mesin panas berlebih)

1.Selang Hidrolik Pecah

m.Dinamo Cas Tidak Mengecas (tidak mengisi kebatrai)

Untuk itu, Aplikasi Sistem Pakar Untuk Mendeteksi Kerusakan Alat Berat Pada PT.Tamako Raya Perdana ini dibuat agar dapat membantu para Operator Alat Berat (Excavator) atau Perusahaan, dan mungkin dapat membantu Mekanik bila lupa akan mekanisme kerja pada Alat Berat (Excavator). Sehingga mereka tidak perlu lagi bersusah payah untuk mendapatkan informasi yang mereka butuhkan dalam menangani masalahmasalah pada Excavator tersebut.

\section{Hasil Analisa dan Rencana Solusi}

Berdasarkan identifikasi masalah dan prinsip kerja yang telah dijelaskan di atas dapat disimpulkan bahwa Aplikasi Sistem Pakar Untuk Mendeteksi Kerusakan Alat Berat Pada PT. Tamako Raya Perdana adalah sebagai berikut :

a. Membuat basis pengetahuan yang menampung data ciri-ciri kerusakan pada Alat. Data lainnya dalam bentuk suatu basis data yang digunakan dalam sistem.

b. Membangun basis pengetahuan untuk menganalisa suatu masalah tertentu dan selanjutnya akan mencari jawaban atau kesimpulan yang terbaik. Sistem ini dapat dikatakan sebagai sistem pengambilan keputusan.

c. Merancang antarmuka pemakai yang dapat menjangkau semua kebutuhan pemakai tanpa mempersulit atau membingungkan user dalam penggunaan sistem ini.

d. Laporan atau report yang dapat menyajikan informasi diagnosa ciri-ciri kerusakan pada Alat, yang diperoleh dari hasil konsultasi terlebih dahulu.

\section{Akuisisi Pengetahuan}

Domain yang ditentukan adalah solusi dari suatu kerusakan. Langkah pertama pada fase ini adalah akuisisi pengetahuan yaitu penggalian atau pengumpulan pengetahuan dari sumbersumber yang tersedia. Sumber pengetahuan suatu kepakaran diperoleh dari pakar domain tertentu maupun kepakaran yang tersedia dalam bentuk materi cetakan.

Pada proses akuisisi pengetahuan dari seorang pakar dicari keputusan, hubungan dan prosedur yang terdapat pada cara menentukan solusi dari suatu kerusakan. Bagian yang menggambarkan hubungan antara fakta-fakta tentang domain dan prosedur-prosedur, setiap objek mempunyai potensi untuk dijadikan basis pengetahuan yang terpisah. Dengan melakukan pengamatan yang hati-hati terhadap sumber pengetahuan, sub domain dari domain yang mungkin dapat di identifikasi agar diperoleh detil yang lengkap. Sebagai contoh setelah dilakukan wawancara dengan pakar (mekanik) didapatkan suatu pengetahuan dalam menentukan solusi atau penangangan dari suatu kerusakan elektrik rusak berdasarkan gejala atau tanda-tanda kerusakan yang dialami, adapun gejala atau tanda-tanda elektrik rusak seperti panel tidak berfungsi, motor gas tidak berfungsi, komputer alat berwarna merah, sedangkan solusi atau penanganan yang harus dilakukan yaitu perbaiki system elektrik. 
JURTEKSI (Jurnal Teknologi dan Sistem Informasi)

Vol. VI No. 1, Des 2019, hlm. 93 - 100

DOI: https://doi.org/10.33330/jurteksi.v6i1.449

Available online at http://jurnal.stmikroyal.ac.id/index.php/jurteksi
ISSN 2407-1811 (Print)

ISSN 2550-0201 (Online)
Setelah didapat pengetahuan dari contoh data tersebut diatas, dapat dibuat perumusan, seperti ditunjukkan pada tabel 1 berikut:

Tabel 1. Hubungan antara gejala, kerusakan dan Solusi yang di sarankan

\begin{tabular}{|c|c|c|c|}
\hline No & Gejala (Tanda-tanda) & Kerusakan & Solusi \\
\hline 1 & $\begin{array}{l}\text { Tenaga boom untuk } \\
\text { mengangkat tidak ada, Seal } \\
\text { Pecah, Oli hidrolik meleleh. }\end{array}$ & $\begin{array}{l}\text { Selinder Boom } \\
\text { Bocor }\end{array}$ & Gangti Seal Boom \\
\hline 2 & $\begin{array}{l}\text { Panel Tidak } \text { Berfungsi, } \\
\text { Motor Gas Tidak Berfungsi, } \\
\text { Komputer Alat Berwarna } \\
\text { Merah. }\end{array}$ & Elektrik Rusak & Perbaiki Sistem Elektrik \\
\hline 3 & $\begin{array}{l}\text { Pergerakan Unit Lambat, } \\
\text { Tenaga Hydrolik Tidak } \\
\text { Optimal, Unit Tidak Ada } \\
\text { Tenaga. }\end{array}$ & $\begin{array}{l}\text { Fuel Injeksi Pump } \\
\text { Lemah }\end{array}$ & Lakukan Kalibrasi Pada Injeksi pump \\
\hline 4 & $\begin{array}{l}\text { Keluar Tanda Error Di Panel } \\
\text { Monitor, Unit Tidak Ada } \\
\text { Tengah. }\end{array}$ & $\begin{array}{l}\text { Selenoid Pompa } \\
\text { Terbakar }\end{array}$ & $\begin{array}{l}\text { Lakukan Pengecekan Pada Instalasi } \\
\text { Kelistrikan (kabel-kabel) Pada Unit. }\end{array}$ \\
\hline 5 & $\begin{array}{l}\text { Bunyi Pada } \\
\text { Oli Keluarel } \\
\text { Motor. }\end{array}$ & $\begin{array}{l}\text { Seal Travel Motor } \\
\text { Bocor }\end{array}$ & $\begin{array}{l}\text { Lakukan Penggantian Pada Seal Group } \\
\text { Travel Motor. }\end{array}$ \\
\hline 6 & $\begin{array}{l}\text { Tenaga Mesin Tidak Ada, } \\
\text { Asap Tebal. }\end{array}$ & $\begin{array}{l}\text { Mesin (Engine) } \\
\text { Ngedrop }\end{array}$ & $\begin{array}{l}\text { Fuel Pump (Injeksi Pump) Perlu di } \\
\text { Revisi atau Kalibrasi, Nozzele di servis. }\end{array}$ \\
\hline 7 & $\begin{array}{l}\text { Rantai Tidak Kuat Berjalan, } \\
\text { Seal Senter Joint Bocor. }\end{array}$ & $\begin{array}{l}\text { Track Lemah } \\
\text { (Tidak Kuat) }\end{array}$ & $\begin{array}{l}\text { Seal Center Joint harus diganti, Stel } \\
\text { Pompa Untuk ke Track Rantai }\end{array}$ \\
\hline 8 & $\begin{array}{l}\text { Motor Gas Tersendat-sendat, } \\
\text { Gas Tidak Mau Naik. }\end{array}$ & $\begin{array}{l}\text { Gas Tidak Bekerja } \\
\text { Dengan Normal }\end{array}$ & $\begin{array}{l}\text { Servis Motor Gas, dan Lakukan } \\
\text { Pengecekan Pada Elektrik Motor Gas. }\end{array}$ \\
\hline 9 & $\begin{array}{llr}\text { Swing } & \text { Terus Berputar } \\
\text { Sewaktu } & \text { Digerakkan, Seal } \\
\text { Motor Swing Bocor. }\end{array}$ & Rem Swing Rusak & $\begin{array}{l}\text { Lakukan Penggantian pada Disc Motor } \\
\text { Swing dan, Lakukan Penggantian Pada } \\
\text { Seal Motor Swing. }\end{array}$ \\
\hline 10 & $\begin{array}{l}\text { Swing Tidak Berfungsi, } \\
\text { Pompa Motor Swing Rusak. }\end{array}$ & $\begin{array}{l}\text { Swing Lemah } \\
\text { (Tidak Ada } \\
\text { Pergerakan } \\
\end{array}$ & $\begin{array}{l}\text { Lakukan Penggantian Pada Selenoid } \\
\text { Swing dan, Lakukan Pengecekan Pada } \\
\text { Pompa Motor Swing. }\end{array}$ \\
\hline 11 & $\begin{array}{lcr}\text { Water } & \text { Pump } & \text { Tidak } \\
\text { Berfungsi, } & \text { Pecah } & \text { Selang } \\
\text { Radiator. } & & \\
\end{array}$ & $\begin{array}{l}\text { Engine Over Head } \\
\text { (Mesin Panas } \\
\text { Berlebih) }\end{array}$ & $\begin{array}{l}\text { Lakukan Pengecekan Pada Water Pump, } \\
\text { jika terdapat kerusakan ganti komponen } \\
\text { water pump dengan yang baru, dan } \\
\text { apabila selang radiator pecah, ganti } \\
\text { dengan selang radiator yang baru. }\end{array}$ \\
\hline 12 & $\begin{array}{l}\text { Bocor Pada Hydrolik Sistem, } \\
\text { Keluar Oli Dari Hydrolik. }\end{array}$ & $\begin{array}{l}\text { Selang Hydrolik } \\
\text { Pecah }\end{array}$ & $\begin{array}{l}\text { Lakukan Penggantian Pada Selang Yang } \\
\text { Pecah }\end{array}$ \\
\hline 13 & $\begin{array}{l}\text { Lampu Tanda Charger di } \\
\text { Panel Monitor Menyala, } \\
\text { Mesin Tidak Bisa Di Starter }\end{array}$ & $\begin{array}{l}\text { Dinamo Cas Tidak } \\
\text { Mengecas (Tidak } \\
\text { Mengisi Ke Aki) }\end{array}$ & $\begin{array}{l}\text { Lakukan Pengecekan di bagian Instalasi } \\
\text { kabel-kabel Kelistrikan pada Unit } \\
\text { (Alat). Lakukan Kalibrasi Pada Dinamo } \\
\text { Cas. }\end{array}$ \\
\hline
\end{tabular}


DOI: https://doi.org/10.33330/jurteksi.v6i1.449

Available online at http://jurnal.stmikroyal.ac.id/index.php/jurteksi

Adapun contoh kaidah Sistem Pakar atau Rule untuk mendeteksi kerusakan alat berat pada PT.Tamako Raya Perdana adalah sebagai berikut:

Tabel 2. Kaidah 1

\begin{tabular}{|l|l|}
\hline Rule & Kondisi dan Aksi \\
\hline If & $\begin{array}{l}\text { Tenaga boom untuk } \\
\text { mengangkat tidak ada }\end{array}$ \\
\hline And & Seal Pecah \\
\hline And & Oli hidrolik meleleh \\
\hline Then & Selinder boom bocor \\
\hline
\end{tabular}

Tabel 3. Kaidah 2

\begin{tabular}{|l|l|}
\hline Rule & Kondisi dan Aksi \\
\hline If & Selinder boom bocor \\
\hline Then & Gangti Seal Boom \\
\hline
\end{tabular}

Tabel 4. Kaidah 3

\begin{tabular}{|l|l|}
\hline Rule & Kondisi dan Aksi \\
\hline If & Panel Tidak Berfungsi \\
\hline And & $\begin{array}{l}\text { Motor Gas Tidak } \\
\text { Berfungsi }\end{array}$ \\
\hline And & $\begin{array}{l}\text { Komputer Alat Berwarna } \\
\text { Merah }\end{array}$ \\
\hline Then & Elektrik Rusak \\
\hline
\end{tabular}

Tabel 5. Kaidah 4

\begin{tabular}{|l|l|}
\hline Rule & Kondisi dan Aksi \\
\hline If & Elektrik Rusak \\
\hline Then & $\begin{array}{l}\text { Perbaiki Sistem } \\
\text { Elektrik }\end{array}$ \\
\hline
\end{tabular}

Tabel 6 Kaidah 5

\begin{tabular}{|l|l|}
\hline Rule & Kondisi dan Aksi \\
\hline If & Pergerakan Unit Lambat \\
\hline And & $\begin{array}{l}\text { Tenaga Hydrolik Tidak } \\
\text { Optimal }\end{array}$ \\
\hline And & Unit Tidak Ada Tenaga \\
\hline Then & Fuel Injeksi Pump Lemah \\
\hline
\end{tabular}

Tabel 7. Kaidah 6

\begin{tabular}{|l|l|}
\hline Rule & Kondisi dan Aksi \\
\hline If & Fuel Injeksi Pump Lemah \\
\hline Then & $\begin{array}{l}\text { Lakukan Kalibrasi Pada } \\
\text { Injeksi pump }\end{array}$ \\
\hline
\end{tabular}

Tabel 8. Kaidah 7

\begin{tabular}{|l|l|}
\hline Rule & Kondisi dan Aksi \\
\hline If & $\begin{array}{l}\text { Keluar Tanda Error Di } \\
\text { Panel Monitor }\end{array}$ \\
\hline And & Unit Tidak Ada Tenga \\
\hline Then & Selenoid Pompa Terbakar \\
\hline
\end{tabular}

Tabel 9. Kaidah 8

\begin{tabular}{|l|l|}
\hline Rule & Kondisi dan Aksi \\
\hline If & Selenoid Pompa Terbakar \\
\hline Then & $\begin{array}{l}\text { Lakukan Pengecekan Pada } \\
\text { Instalasi Kelistrikan (kabel) } \\
\text { Pada Unit. }\end{array}$ \\
\hline
\end{tabular}

Tabel 10. Kaidah 9

\begin{tabular}{|l|l|}
\hline Rule & Kondisi dan Aksi \\
\hline If & Bunyi Pada Travel Motor \\
\hline And & $\begin{array}{l}\text { Oli Keluar Dari Travel } \\
\text { Motor }\end{array}$ \\
\hline Then & Seal Travel Motor Bocor \\
\hline
\end{tabular}

Tabel 11. Kaidah 10

\begin{tabular}{|l|l|}
\hline Rule & Kondisi dan Aksi \\
\hline If & Seal Travel Motor Bocor \\
\hline Then & $\begin{array}{l}\text { Ganti Seal Group Travel } \\
\text { Motor. }\end{array}$ \\
\hline
\end{tabular}

\section{Perancangan Mesin Inferensi}

Metode penalaran yang digunakan dalam sistem pakar ini adalah penalaran pelacakan maju (Forward Chaining) yaitu dimulai dari sekumpulan fakta-fakta tentang suatu tanda-tanda kerusakan yang diberikan oleh pengguna sebagai masukan sistem, untuk kemudian dilakukan pelacakan sampai tujuan akhir 
DOI: https://doi.org/10.33330/jurteksi.v6i1.449

Available online at http://jurnal.stmikroyal.ac.id/index.php/jurteksi

berupa mendeteksi kerusakan alat berat dan penjelasan tentang jenis kerusakan yang dialami serta solusi perbaikan atau penanggulangannya.

\section{Tes Dan Implementasi}

Pada bagian ini akan dijelaskan tentang pengimplementasian hasil yang telah dibuat dalam kajian sebelumnya, yaitu tampilan form-form yang terdapat pada aplikasi Sistem Pakar ini.

a. Menu Utama

Form Menu Utama ini adalah tampilan awal sebelum User melakukan prosesproses selanjutnya.

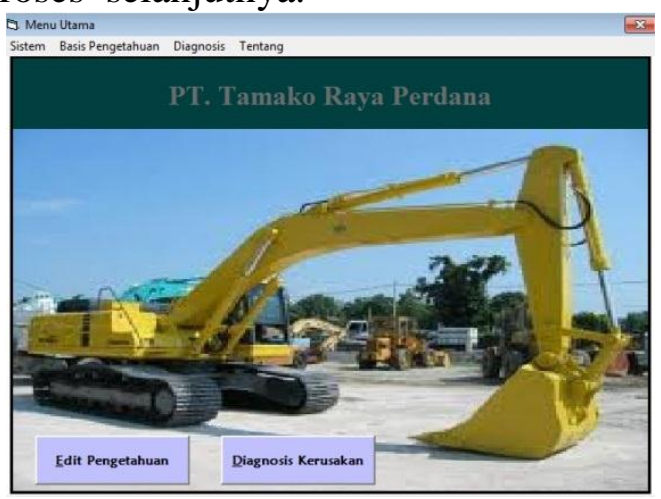

Gambar 2. Form Menu Utama

b. Validasi User

Untuk melanjutkan ke proses berikutnya, bagi Admin dan Pakar terlebih dahulu melakukan proses login (Gambar 4.23)

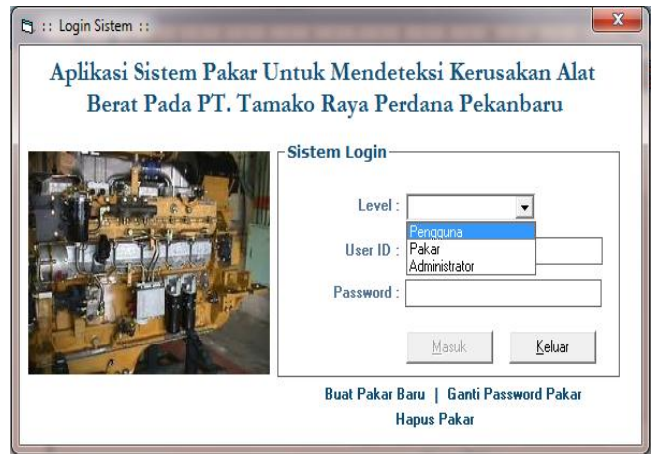

Gambar 3. Form Login
Setelah melakukan login, user akan dibawa ke form utama lagi untuk memulai melakukan diagnosis, lihat Gambar 4.24

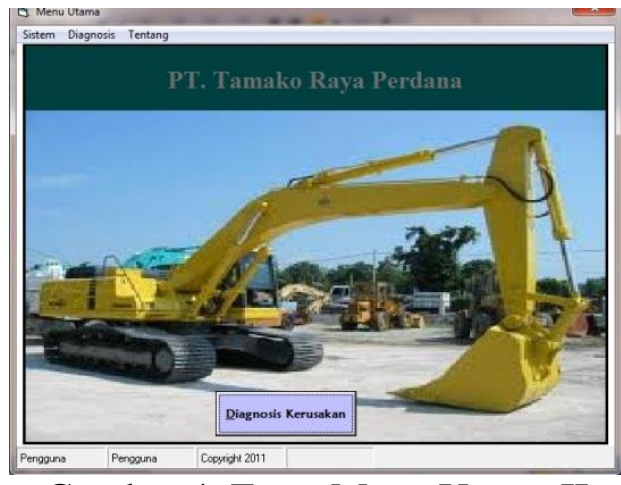

Gambar 4. Form Menu Utama II

c. Pilih Kerusakan

Form ini merupakan perkiraan pilihan kerusakan, yang nantinya akan membawa user pada pertanyaan, yaitu tentang tanda-tanda kerusakan yang dialami oleh Unit (Alat).

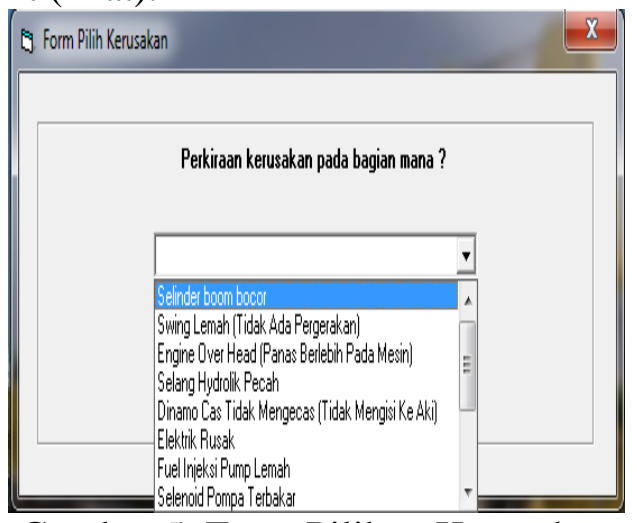

Gambar 5. Form Pilihan Kerusakan

\section{d. Proses Pertanyaan}

Form ini merupakan proses-proses dari pertanyaan yang diberikan oleh program dan juga sebagai input data yang user diarahkan pada sebuah kesimpulan atau output, untuk lebih jelasnya lihat form diagnosis kerusakan berikut. 
DOI: https://doi.org/10.33330/jurteksi.v6i1.449

Available online at http://jurnal.stmikroyal.ac.id/index.php/jurteksi

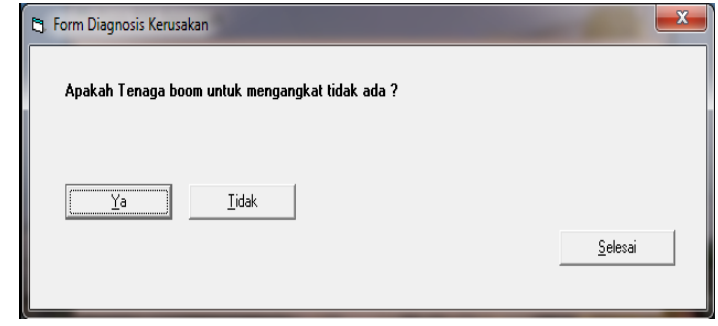

Gambar 6. Form Diagnosis Kerusakan

e. Hasil Diagnosis

Setelah Pertanyaan-pertanyaan selesai dijawab maka user akan menjumpai hasil diagnosis.

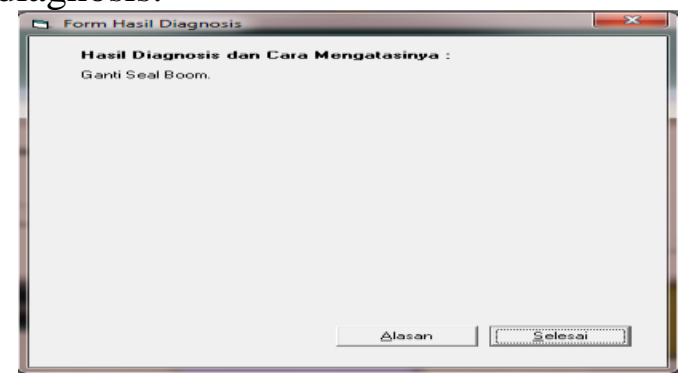

Gambar 7. Form Hasil Diagnosis

f. Form Solusi atau Penanganan Form solusi atau penanganan ini adalah cara untuk mengatasi yang ditawarkan oleh program.

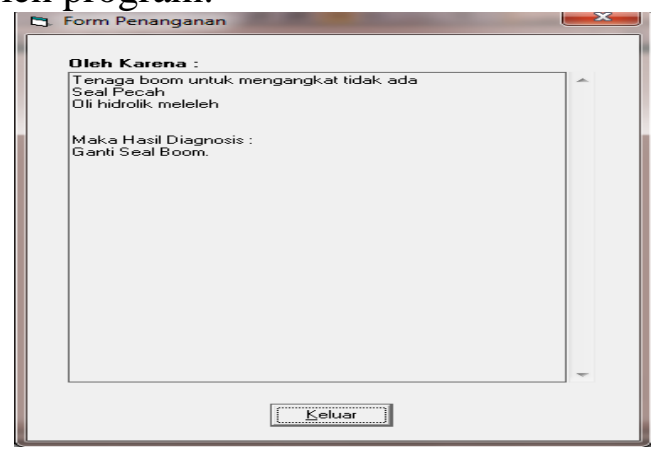

Gambar 8. Form Solusi atau Penanganan

\section{SIMPULAN}

Adapun beberapa kesimpulan yang dapat diambil oleh penulis selama penelitian ini adalah sebagai berikut:

1. Sistem Pakar yang telah dibuat diharapkan dapat membantu Mekanik dan juga Operator Alat dalam mendeteksi kerusakan alat berat dengan cepat.

2. Rule-rule yang dibuat sudah memiliki tingkat akurasi yang cukup, sehingga dapat sebagai pendeteksi yang cukup akurat kepada pengguna.

3. Aplikasi sistem pakar telah dibuat dinamis, sehingga apabila terjadi penambahan data, program aplikasi ini tetap dapat digunakan.

4. Penggunaan metode forward chaining pada inference engine cocok untuk permasalahan yang dibahas.

5. Fasilitas Edit yang ada haruslah digunakan oleh orang yang mengerti Sistem Pakar, sehingga tidak terjadi kesalahan baik pada pengoperasiannya maupun terhadap kesimpulan yang dihasilkan aplikasi ini.

\section{DAFTAR PUSTAKA}

[1] Turban, E., 1995. Decision Support System and Expert Systems. USA: Prentice Hall International Inc.

[2] Kusrini, Aplikasi Sistem Pakar, Andi, Yogyakarta 2008.

[3] Arhami Muhammad, Konsep Dasar Sistem Pakar, Andi, Yogyakarta 2005. 